\title{
Analysis of the role of social support - cognitive psychology and emotional process approach
}

\author{
Mohammad Heydari (1), Zhou Xiaohu (2), Mahdiye Saeidi (3), Kin Keung Lai (4), \\ Yufan Shang (5), Zheng Yuxi (6)
}

(1) School of Economics and Management, Nanjing University of Science and Technology, Nanjing, Jiangsu, China; (2) School of Economics and Management, Nanjing University of Science and Technology, Nanjing, China; (3) Payame Noor University, Department of Tehran West, Iran; (4) College of Economics, Shenzhen University, Shenzhen, China; (5) School of Management, Xi'an Jiaotong University, Xi'an, Shaanxi, China; (6) Faculty of Economics and Management, East China Normal University, Shanghai, China

This article is distributed under the terms of the Creative Commons Attribution Noncommercial License (CC BY-NC 4.0) which permits any noncommercial use, distribution, and reproduction in any medium, provided the original author(s) and source are credited.

\begin{abstract}
The eyes are extremely important for communication. The muscles around the eyes express emotional states, and the size of the pupil signals whether a person is aroused and alert or bored and fatigued. Pupil size is an overlooked social signal, yet is readily picked up by observers. Observers mirror their pupil sizes in response, which can influence social impressions. Pupil diameter is enhanced in a variety of emotional contexts, including viewing pictures, listening to sounds, and during the threat of shock. This study shows that people associate positive faces with large pupil sizes and negative faces with small pupil sizes. Although workplace social support has been described as a profoundly emotional activity, little is known about the emotional demands faced by employees or how these impacts on their well-being. This study examined relationships between 'emotional labor,' burnout (emotional exhaustion, depersonalization, and personal accomplishment), and job satisfaction in a sample of an employee who works in the banking sector or manufacturing sector. Also examined was whether workplace social support moderated any relationships found between emotional labor and strain. The relationship between job experience and emotional labor was also investigated.
\end{abstract}

Key Words: Cognitive Psychology, Emotion, Well-Being, Pupil, Banach Space

Eur J Transl Myol 2020; 30 (3): 8975. doi: 10.4081/ejtm.2020.8975

The eyes are extremely important for communication.

The muscles around the eyes express emotional states and the size of the pupil signals whether a person is aroused and alert or bored and fatigued. Pupil size is an overlooked social signal, yet is readily picked up by observers. Observers mirror their pupil sizes in response, which can influence social impressions. In a landmark study Hess shown that individuals with large pupils are perceived more positively than individuals with small pupils. ${ }^{1}$ In that behavioral study, participants were asked to draw pupils in line drawings of faces with empty irises, and they drew large pupils in the happy face, and small ones in the angry face. The current study tested 628 participants (aged 20-80 years old) from the banking sector or manufacturing sector in China and extended this work by showing that this association between large (small) pupils and a positive (negative) impression develops overage and is absent in employees. Several explanations for how individuals through interactions with close others learn that large pupils mean care, interest and attention and small pupils the opposite, are discussed. To conclude, this study shows that pupil size and emotion perception are intertwined but that their relationship develops overage. Although workplace support has been described as a profoundly emotional activity, little is known about the emotional demands faced by employees or how these impacts on their wellbeing. This study examined relationships between "emotional labor", burnout (emotional exhaustion, depersonalization, and personal accomplishment), and job satisfaction in a sample of Chinese employees. Also examined was whether workplace social support moderated any relationships found between emotional labor and strain. The relationship between job experience and emotional labor was also investigated. 628 employees working in the banking sector or the manufacturing sector in China completed questionnaires. 
Significant associations were observed between emotional labor and all outcomes, with a positive relationship found between emotional labor and personal accomplishment. Some evidence was found that social support mitigates the negative impact of emotional demands on emotional exhaustion, feelings of personal accomplishment and job satisfaction. More experienced employees reported higher levels of emotional labor. Findings highlight the need for employees of training programs to raise awareness of the emotional demands of workplace support and consider ways to enhance emotion regulation skills in experienced as well as recently qualified staff. A body of research indicates that employees are more vulnerable to work-related stress, psychological distress, and burnout than many other

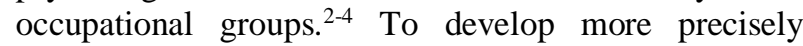
targeted interventions to enhance well-being in the profession, insight is needed into the aspects of the employee role in the organization that threatens psychological health and job satisfaction. Studies conducted in China and other countries have highlighted a wide range of stresses that are commonly experienced by employees. These encompass job-specific hazards, such as employee preparation, large organization sizes, poor pupil motivation and pupil misbehavior, ${ }^{5-8}$ as well as more general stressors such as time pressures, administrative demands, lack of human and technical resources and a perceived imbalance between efforts and rewards.9-16, 115 Studies of various occupational groups have found the emotional demands intrinsic to many types of jobs to be a considerable source of strain. ${ }^{17}$ Workplace support has been described as a profoundly emotional activity, ${ }^{18}$ requiring the effective management of personal emotions and the ability to engender the desired emotional state in others. Employees are expected to safeguard the emotional well-being of their pupils as well as their physical safety. ${ }^{19,20}$. They are also required to model successful emotional control at all times, treating pupils with warmth and compassion and suppressing any feelings of impatience or anger. ${ }^{21}$ It has recently been argued that employees are increasingly expected to manage their emotions in ways similar to service sector employees. ${ }^{22,112}$ The concept of emotional labor was first introduced by Hochschild (1983) based on her studies of cabin crew, ${ }^{23}$ but subsequent research has found emotional labor to be commonplace in a number of human service occupational groups and a considerable predictor of strain. ${ }^{17,24}$ As yet, however, little is known about how the emotional labor, involved in the employee role, may impact on the well-being of employees. Most of what is known has been gleaned from reviews, commentaries and ethnographic studies, ${ }^{19,25-27}$ or small samples of employees working in the post-compulsory sector. $^{28,29}$ A notable exception is a recent study conducted by Philipp and Schupbach (2010) with a sample of German teachers. ${ }^{30}$ Evidence was found that emotional labor was positively related to levels of emotional exhaustion. To extend knowledge of staff stress and inform the development of effective interventions to enhance well-being in the profession, the present study examines relationships between emotional labor, burnout and job satisfaction.

\section{Materials and Methods}

Pupil diameter is modulated by emotional arousal in a number of different contexts, including picture viewing, in which larger changes in pupil diameter are found when viewing highly arousing pleasant or unpleasant, compared to neutral, scenes. ${ }^{31-34}$ Pupil dilation has also been reported when participants listen to pleasant or unpleasant, compared to neutral sounds, ${ }^{35}$ and when participants anticipate the upcoming presentation of an adverse event. For example, Bitsios, Szbadi, and Bradshaw (1996) found that pupil diameter was enhanced when participants were under threat of shock exposure, compared to when no shock exposure as possible. ${ }^{36}$ In the current study, we investigated whether pupil diameter is similarly modulated by emotion during mental imagery. Because emotional imagery is a key component in the assessment, ${ }^{37,38}$ and treatment of mental health disorders, ${ }^{39,40}$ pupil diameter could prove to be a useful psychophysiological index in a number of clinical venues. In this study, brief texts were presented that described a variety of emotional and neutral events. The participant was instructed to silently read each script and imagine the events described vividly as an active participant. Previous studies investigating physiological and neural reactivity during narrative imagery found that modulation of emotion begins while the participant is reading the script, and is sustained during a subsequent imagery period. For instance, skin conductance is enhanced when reading emotional scripts, and the difference is sustained in the imagery interval following the script offset. ${ }^{41}$ Relatedly, greater BOLD activation is found in the medial prefrontal cortex and nucleus accumbens when participants read pleasant scripts, which again continues during the imagery interval following script offset. ${ }^{42}$ These temporal parameters are reasonable, since reading a text, comprehending a text, and preparing to imagine the event involve similar, if not identical, cognitive processes that can begin as soon as the constituent information becomes available. An alternative imagery procedure that requires participants first to memorize to-be-imagined script, ${ }^{43}$ eliminates the need for visual input, which could prove beneficial in studying pupil diameter, but imposes a relatively larger working memory burden on the participant, potentially affecting pupil diameter changes. ${ }^{44,45}$ For this reason, scripts were presented visually in the current study. Importantly, scripts were selected to be of similar character length and did not differ in brightness. Moreover, each script was first to read and rated before the imagery session specifically to facilitate rapid and immediate image construction during psychophysiological measurement. ${ }^{42,46}$ Whereas previous studies have measured peripheral (e.g., skin conductance, 
heart rate) and central (e.g., BOLD) indices of affective engagement, in this study, we explore pupillary changes occurring during emotional imagery. Pupil diameter changes are mediated by both parasympathetic and sympathetic action of the nervous system, which influences the sphincter and dilator muscles of the pupil, respectively. On the one hand, pupil diameter is greater when participants perform a difficult subtraction task compared to an easier addition task, and pharmacological manipulations suggest that this cognitive difference is likely modulated by inhibition of the sphincter muscle, mediated by parasympathetic activity, which reduces pupil constriction. ${ }^{47}$ On the other hand, during emotional picture viewing, enhanced pupil diameter is found when participants view either highly arousing pleasant or unpleasant scenes, and this difference appears to be mediated by pupil dilation, probably due to differences in sympathetic action on the dilator muscle. ${ }^{48}$

\section{Emotional labor, burnout and job satisfaction}

Emotional labor is typically conceptualized as the degree of dissonance between emotions that are genuinely felt and those that the job requires to be expressed or suppressed. ${ }^{17}$ There is evidence that emotional labor can impair employee well-being, as psychological effort is frequently required to 'regulate' emotions to comply with organizational or professional expectations. ${ }^{49}$ Particularly strong relationships have been found between emotional labor and emotional exhaustion..$^{50-52}$ Emotional exhaustion is a credible reaction to sustained demands for emotional regulation, but relationships with the other two dimensions of burnout (depersonalization and reduced feelings of personal accomplishment) are also plausible in the teaching profession. Sustained emotional labor may lead to employees depersonalizing their pupils, resulting in less sympathetic and more cynical attitudes towards them. A review of the literature implies that associations between emotional labor and feelings of personal accomplishment might be less clear cut. It could be argued that attempting to manage an emotionally demanding job over time might erode feelings of personal accomplishment and enhance negativity towards the self and the job, ${ }^{49}$ but studies of other "caring" professions suggest that such feelings might be heightened. ${ }^{24}$ As employees are a high-risk group for burnout, ${ }^{53,54}$ insight into the role played by emotional labor in the burnout process can only enhance understanding of employee well-being. Studies that have examined relationships between emotional labor and job satisfaction have yielded mixed findings. Some have found that emotional labor impairs job satisfaction as it may stifle the expression of true emotions and also deplete emotional resources, ${ }^{17,55,56}$ whilst others conclude that the successful management of emotional demands can enhance feelings of satisfaction with the job role. . $2,57-^{-}$ ${ }^{59}$ It has been suggested that the impact of emotional labor on job satisfaction depends upon the context in which it is performed. ${ }^{60,61}$ There is some evidence that employees see emotional labor as intrinsic to their work, and believe that well-developed emotional regulation skills are required for maximum professional effectiveness. ${ }^{62}$ Positive relationships between emotional labor and job satisfaction in this occupational context might, therefore, be expected.

\section{Social support, emotional labor, and burnout}

This study investigates the potential buffering role of workplace social support on any relationships found between emotional labor, burnout, and job satisfaction. Research conducted in occupational settings has found perceptions of a supportive working climate to be linked with enhanced health status, job satisfaction as well as other positive outcomes. ${ }^{63}$

Two processes have been proposed to elucidate the beneficial effect of social support. ${ }^{64}$ The direct effects model suggests that social support has a positive impact on well-being regardless of the amount of stress experienced.

The moderator or buffer model postulates that social support is a resource that is most effective for people who are experiencing high levels of stress. There is evidence to support both theoretical models in predicting burnout and other affective outcomes, but some studies have failed to find evidence for the buffering effect. ${ }^{65,66}$ Several studies have found negative relationships between workplace social support and burnout in samples of teachers, thus supporting the main effects model. ${ }^{67}$ Other studies of employees provide evidence that support can buffer the negative impact of workrelated stressors. ${ }^{16,68}$ There are reasons to believe that social support at work is a theoretically plausible moderator of emotional labor and strain in occupational settings. Firstly, employees who experience more supportive interpersonal relationships at work may find fulfilling the emotional demands of their job role to be less onerous. Secondly, employees who feel more supported may report lower levels of emotional labor as the 'appropriate' emotional response arises more spontaneously. Thirdly, the ability to disclose emotional events and 'true' feelings in a supportive environment might help employees develop more successful coping strategies that protect them against health risks. ${ }^{49}$ As yet, few studies have examined the role played by social support in the emotional labor process. A study of customer service representatives conducted by Abraham (1998) reported an interaction between social support and emotional labor on levels of job satisfaction. ${ }^{55}$ Similarly, a more recent study by Duke, Goodman, Treadway, and Breland (2009) found that social support attenuated the negative impact of emotional labor on job satisfaction and performance in a sample of retail workers. ${ }^{69}$

As little is known about whether social support protects employees from the negative impact of emotional labor, this study examines whether workplace support might help employees manage the emotional demands of their work. 


\section{Emotional labor and job experience}

As an insight into the role played by teaching experience in the emotional labor process will help inform more precisely targeted interventions, this will be examined in the present study. Research conducted with service sector employees suggests that the longer an employee is required to perform emotion work, the more negative the consequences for well-being due to the gradual erosion of emotional resources. ${ }^{49,70}$ It has also been argued, however, that employees might become gradually 'desensitized' to the emotional demands of their work as they develop more effective coping strategies and utilize workplace social support more effectively. ${ }^{71}$ Consequently, positive or negative relationships between emotional labor and job experience might be expected.

Conceptual Modeling: Definition, Purpose, and Benefits This study investigated relationships between emotional labor and burnout (emotional exhaustion, depersonalization, and personal accomplishment) and job satisfaction in a sample of Chinese employees. Associations between emotional labor and job experience are also examined. Finally, whether workplace social support moderates the relationship between emotional labor and strain is investigated.

\section{Banach Space Model in this Research}

(See Appendix for the main results).

For defining the Banach Space, we give necessary and sufficient conditions for the existence of solutions.

We consider the second-order nonlinear difference equations of the form:

$$
\Delta\left(r_{n-1} \Delta x_{n-1}\right)+p_{n} f\left(x_{n-k}\right)=h_{n}
$$

We show that there exists a solution $\left(\mathrm{x}_{\mathrm{n}}\right)$, which possesses the asymptotic behavior:

$$
\left\|x_{n}-a \sum_{j=0}^{n-1}\left(1 / r_{j}\right)+b\right\|=0(1), a, b \in \mathbb{R}
$$

In this paper, we extend the results of Agarwal (1992), ${ }^{72}$ Dawidowski et al. (2001), ${ }^{73}$ Drozdowicz, and Popenda (1987), ${ }^{74}$ M. Migda (2001), ${ }^{75}$ and M. Migda and J. Migda (1988). ${ }^{76}$ We suppose that $\mathrm{f}$ has values in Banach space and satisfies some conditions concerning the measure of noncompactness and measure of weak noncompactness. Let $\mathbb{C}$ be the set of complex numbers and let $\mathbb{R}$ be the set of real numbers and $l_{1}(\mathbb{C})$ the space of complexvalued sequences $\left(C_{n}\right)$ such that:

$$
\left\|\left(C_{n}\right)\right\|_{1}:=\sum_{i=1}^{\infty}\left|C_{n}\right| \prec \infty
$$

Let $(X,\|\|$.$) be a complex (real) Banach space and$ $l_{\infty}(X)$ denote the space of bounded sequences $x=\left(x_{n}\right)$ in $\mathrm{X}$ with the norm:

$$
\|x\|_{\infty}=\left\|\left(x_{n}\right)\right\|_{\infty}=\sup _{n}\left\|x_{n}\right\|
$$

This norm $l_{\infty}(X)$ is a Banach space.

In this paper, we are concerned with the difference equation in Banach space:

$$
\Delta\left(r_{n-1} \Delta x_{n-1}\right)+p_{n} f\left(x_{n-k}\right)=h_{n}, \quad n \in \mathbb{N}
$$

where $\Delta$ is the forward difference operator, that is,

$\Delta x_{n}=x_{n+1}-x_{n}$,

$\Delta^{2} x_{n}=\Delta\left(\Delta x_{n}\right)$,

and $f: X \rightarrow X$

By a solution of (5), we understand a sequence $x=\left(x_{n}\right)$ in $l_{\infty}(X)$ which satisfies (5).

The results obtained here generalize some results of $\mathrm{M}$. Migda and J. Migda. ${ }^{9,10}$ In M. Migda and J. Migda, ${ }^{10}$ the second-order difference equation of the form:

$\Delta^{2} x_{n}=a_{n} \varphi\left(x_{n+k}\right), n=1,2, \ldots, k=0,1,2, \ldots$,

was considered. The authors give a condition when this equation has a solution, asymptotically equal to $c, c \in \mathbb{R}$.

\section{Pupils Size and Diameter}

The eyes are extremely important for communication. The muscles around the eye's express emotional states, and the size of the pupil signals whether a person is aroused and alert or bored and fatigued. Pupil size is an overlooked social signal, yet is readily picked up by observers. Observers mirror their pupil sizes in response, which can influence social impressions. Pupil diameter is enhanced in a variety of emotional contexts, including viewing pictures, listening to sounds, and during the threat of shock.

In this study, we investigated pupil diameter changes during emotional imagery. Participants imagined scenes describing pleasant, unpleasant, or neutral events while the pupil diameter was continuously recorded. Second, by second changes in pupil diameter were analyzed to determine whether, and when, modulation of the pupil as a function of hedonic content is found. This part of the study aims to get insight into the question of whether the positive evaluation of someone with large pupils is innate or prone to changes overage. To that extent, we adapted a very simple paradigm from Hess (1975), ${ }^{1}$ where he showed adult participants two-line drawings of a face of a happy and angry person. The eyes of these line drawings did not contain pupils and participants were asked to draw this in. What was observed was that participants drew large pupils in the happy face and small pupils in the angry face. The aim of the current study is threefold. The first aim of this study is to replicate this earlier finding. A second aim is to investigate potential alterations overage. A third aim is to explore gender differences. While Hess $(1975)^{1}$ did observe sex 
$\mathbf{A}$

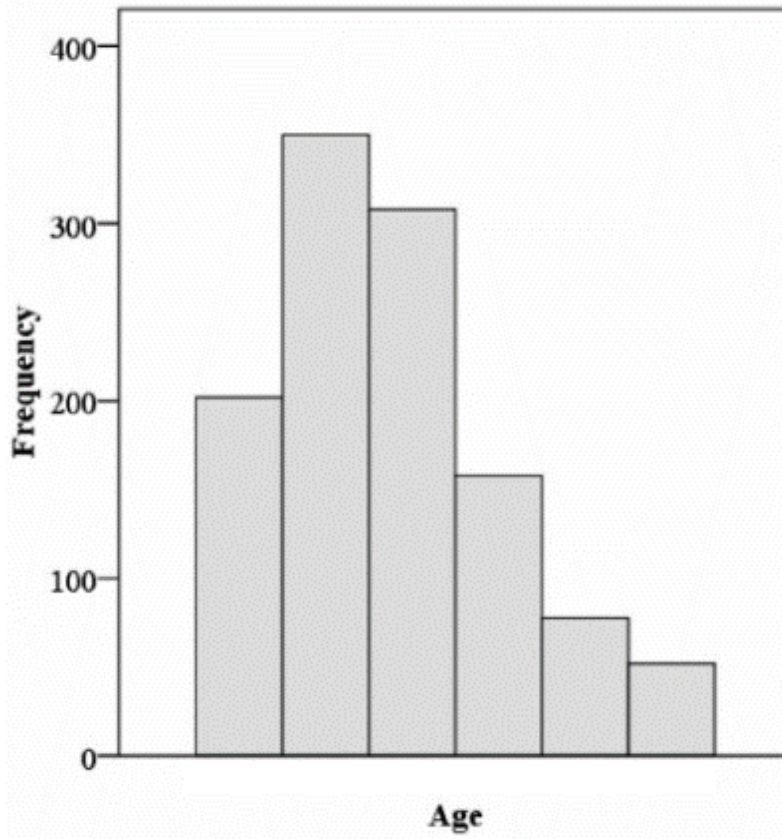

B

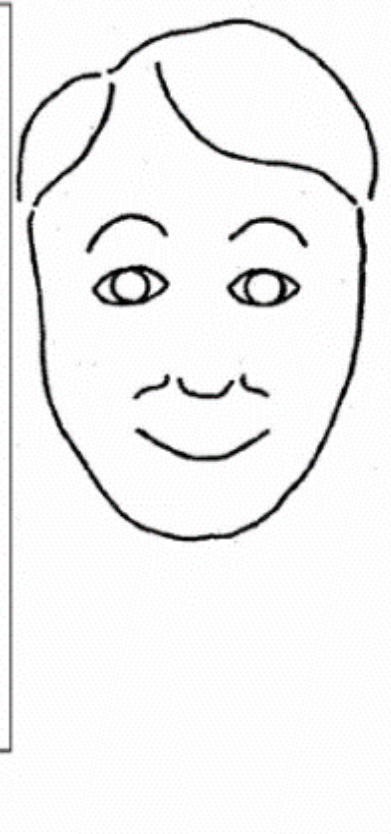

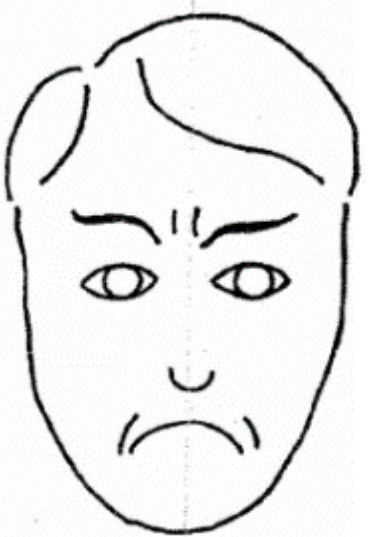

Fig 1. Methods of the study. (A) Frequency graph of the participant sample, divided into age blocks (for visualization purposes only). (B) The drawings that were used in the study (adapted from Hess, 1975). ${ }^{1}$

differences in the perception of pupil size, Kret and de Dreu (2017) did not. ${ }^{77}$ Thus, whether this putative difference in drawn pupil size in the happy compared to angry faces is modulated by gender is an open question. In the current study, a large number of subjects with a wide age range was asked to draw pupil sizes in the line drawings first used in the study by Hess (1975). ${ }^{1}$

\section{Stimuli}

Two line-drawings of a happy and angry face were taken from Hess (1965) ${ }^{78}$ and printed out. See Figure 1.

\section{Procedure}

Participants were told that the pupils were missing in the printed drawing and asked to draw them and to color them in. The order at which the drawings were handed out was randomized. After data collection, all line drawings were scanned and imported into Adobe Photoshop. Next, the number of pixels that fell within the outline of the drawn pupils were counted and served as the dependent variable.

\section{Ethical considerations}

This study was approved by the Nanjing University of Science and Technology, School of Economics and Management. This study was conducted in accordance with the Declaration of Mohammad Heydari Ph.D. dissertation. All of the participants signed informed consent prior to participating in the study. For more information please contact [Mohammad_Heydari@njust.edu.cn].

\section{Statistical analysis}

Data were analyzed in a two-level Generalized Mixed Model, implemented in SPSS. The two drawings were nested within participants. As the drawn pupil sizes were significantly skewed to the right, a gamma regression was selected (similar to log-transforming the data). "Emotion" (angry and happy) was included as a fixed factor and the intercept as a random factor.

\section{Results}

As predicted, the main effect of emotion was observed. Participants drew larger pupils in happier face than in the angry face $F(1,1,141)=13.302, p<.001$.

However, when adding Age and Sex of Participant and their interactions with Emotion to the model, the main effect of Emotion disappeared $(p=.301)$. To get to the best fitting, yet most parsimonious model, nonsignificant factors were dropped one by one, starting with the three-way interaction, then the two two-way interactions with Sex of Participant and the final factor that was dropped was Sex of Participant.

With the final model, a significant interaction effect was observed between Emotion and Age of Participant1F $(1,1,131)=12.464, p<.001$, showing that the difference in the size of the pupils drawn in the happy face as compared to those drawn in the angry face, increased with age. When investigating the effect of Age of Participant separately per Emotion Category, this effect turned out to be driven by the angry faces $F(1,565)=$ 14.926, $\mathrm{p}<.001$ (happy: $\mathrm{p}=.451$ ). Thus, overage, participants started to draw the pupil sizes in the angry 


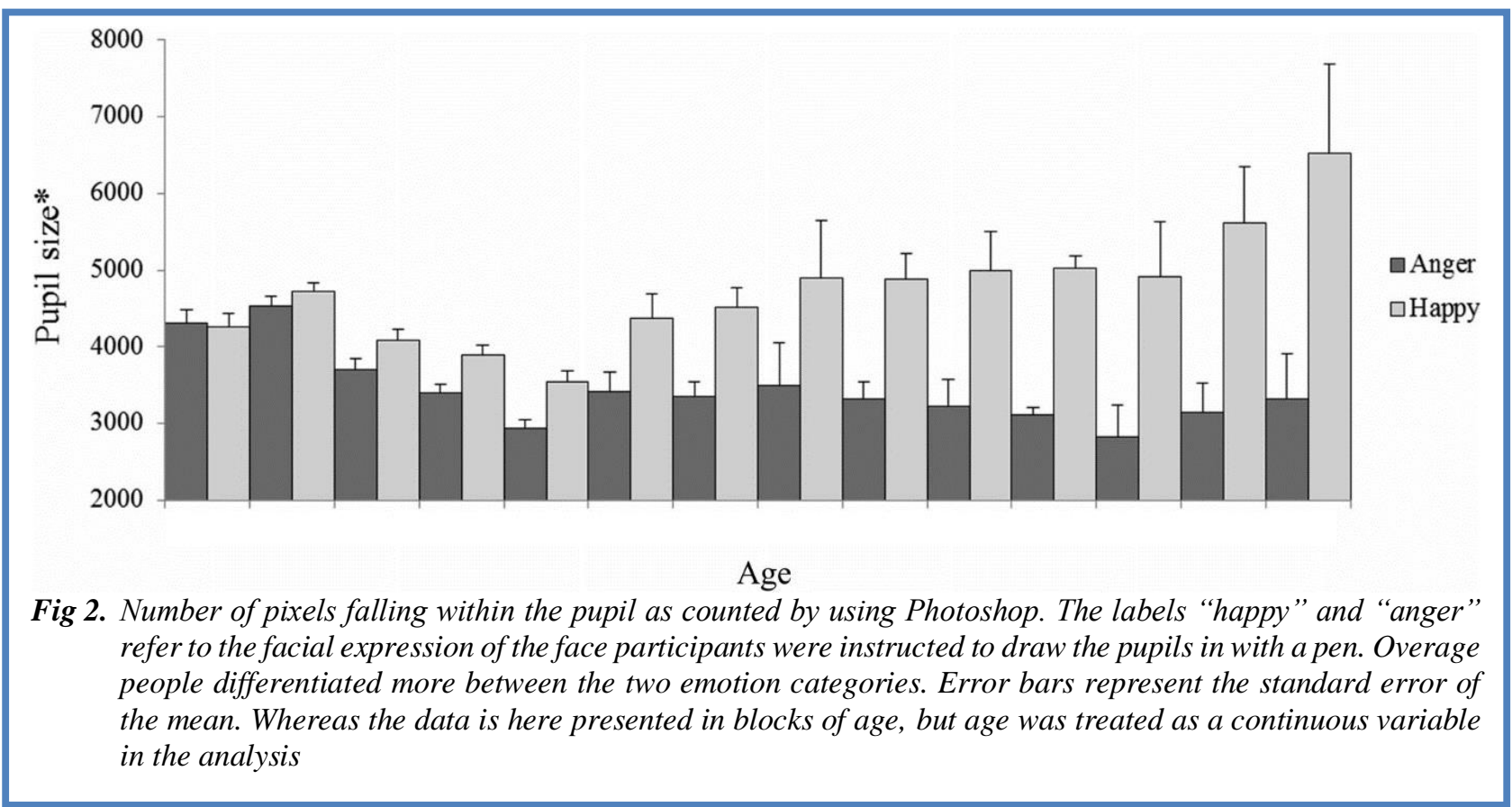

face smaller (Figure 2). There was no main effect of Emotion $(p=.281)$ and no main effect of Age $(p=.203)$. Age distribution of participants in this study is $(18-28$; 28-38; 38-48; 48-58; 58-68; 68-78).

According to Hess (1975) "When we say that someone's eyes are soft, hard, beady, cold or warm, we are in most instances referring only to a certain aspect of that person's eyes: the size of the pupils". Large pupils are generally perceived positively and small pupils negatively. ${ }^{79-82}$ Taking a developmental perspective, the findings of the current study suggest that these associations are most likely learned rather than hardwired. In this study, participants from different ages were asked to draw pupils in two-line drawings of a happy and angry face. Overall, participants drew larger pupils in the happy compared to the angry face, and this study in addition to that replicates Hess (1975) ${ }^{1}$ earlier description of this phenomenon. Interestingly though, the current study shows that this difference in pupil size drawn in the happy versus angry face continues to increase throughout people's lifetime and is absent in young children, independent of the gender of the participant.

\section{Data reduction}

Pupil diameter was converted offline from arbitrary units to millimeters. Linear interpolation was used to estimate pupil size for samples in which the pupil was occluded due to blinking with the ASL Results software. Five participants were not included in the final analysis due to unsuccessful pupil discrimination on more than $15 \%$ of trials during the imagery task. For the remaining 30 participants, trials with insufficient pupil discrimination for over $15 \%$ of the trial were excluded from the analysis (mean percentage of trials excluded52\%). For each trial, pupil diameter in the $1 \mathrm{~s}$ before script presentation was subtracted from each of the following pupil samples. For each subject and trial, the mean change in pupil diameter was then calculated in $1-\mathrm{s}$ intervals for $11 \mathrm{~s}$, which included the 6-s, period in which the script was on the screen and the following 5-s imagery period before the onset of the earliest light probe. Analyses of variance (ANOVAs) were conducted with hedonic content (pleasant, neutral, and unpleasant) and time (1-s intervals) as repeated measures factors, and follow-up ANOVAs were conducted separately on each 1-s interval to decompose significant interactions.

\section{Script analysis}

In this analysis, script, rather than a participant, served as the unit of analysis in a regression that used the average pleasure and arousal ratings for each script (across participants) to predict pupil diameter change. Figure 3 illustrates the change in pupil diameter for each second following script onset as a function of hedonic content. A repeated-measures ANOVA indicated main effects of time, $\mathrm{F}(10,20)=15.7, \mathrm{p}<.001, \eta \rho^{2}=.351$, and hedonic content, $\mathrm{F}(2,28)=4.6, \mathrm{p}<.05, \eta \rho^{2}=.136$, as well as an interaction of time and content, $\mathrm{F}(2,28)=3.3, \mathrm{p}<.005$, $\eta \rho^{2}=.103$. Simple main effects tests were conducted for each time bin, and indicated that pupil diameter varied with hedonic content beginning in the third time bin after script onset, which was then sustained across the imagery period (time bins 3-11: Fs $(2,28)=6.6,6.2,4.4,5.4,2.4$, $3.7,4.8,6.1,6.5$, ps <.05 except time bin 7, p5.1). Significant quadratic trends indicated that pupil diameter when imagining pleasant or unpleasant scenes was larger than when imagining neutral scenes at each time bin (time bins 3-11: Fs $(2,28)=12.5,11.9,7.9,5.4,4.1,6.3$, $7.8,9.4,10.0$; ps<.05, except time bin 7, p5.05). Consistent with this, when pupil diameter was averaged 


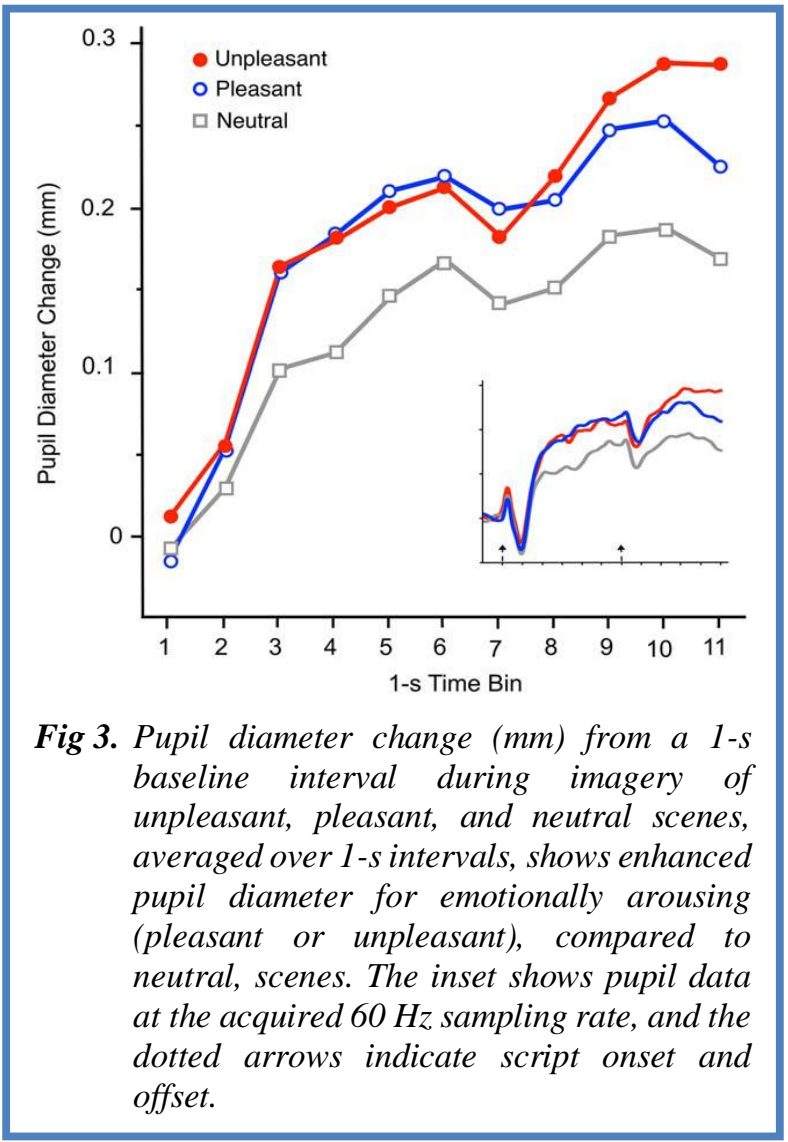

across the effective imagery interval (time bins 3-11), there was a significant main effect of content, $F(2$, $28)=5.4, p<.01$, and follow-up comparisons indicated enhanced pupil diameter when imagining unpleasant $(\mathrm{M}=0.23, \mathrm{SD}=0.19 ; \mathrm{F}(2,28)=5.7, \mathrm{p}<.05)$ or pleasant $(\mathrm{M}=0.22, \mathrm{SD}=0.19 ; \mathrm{F}(2,28)=10.2, \mathrm{p}<.005)$, compared to neutral $(\mathrm{M}=0.15, \mathrm{SD}=0.21)$ events. Figure 4 shows pupil diameter changes to the brief light probes presented during imagery. A large transient constriction is evident that was not modulated by hedonic content. Pleasure and arousal ratings for each script were used to predict pupil diameter in the interval in which emotional modulation was significant (average of time bins 3-11). Rated emotional arousal accounted for significant variations in the amplitude of pupil dilation, $\mathrm{F}(1,44)=5.8, \mathrm{p}<.05$, r5.35, but there was no relationship between rated pleasure and pupil dilation.

\section{Emotional labor}

This was measured by a five-item scale developed to assess emotional dissonance by Zapf et al. (1999). ${ }^{17}$ This scale examines how often respondents were required to perform emotional labor on a five-point scale ranging from $1=$ 'very rarely/never' to $5=$ 'very often.' An example item is: 'How often do you have to display emotions that do not agree with your true feelings?' This measure has been used widely in a range of occupational groups including employees. ${ }^{30,83}$ Mean scores were calculated across items with higher scores representing higher levels of emotional labor $(\mathrm{a}=0.90)$.

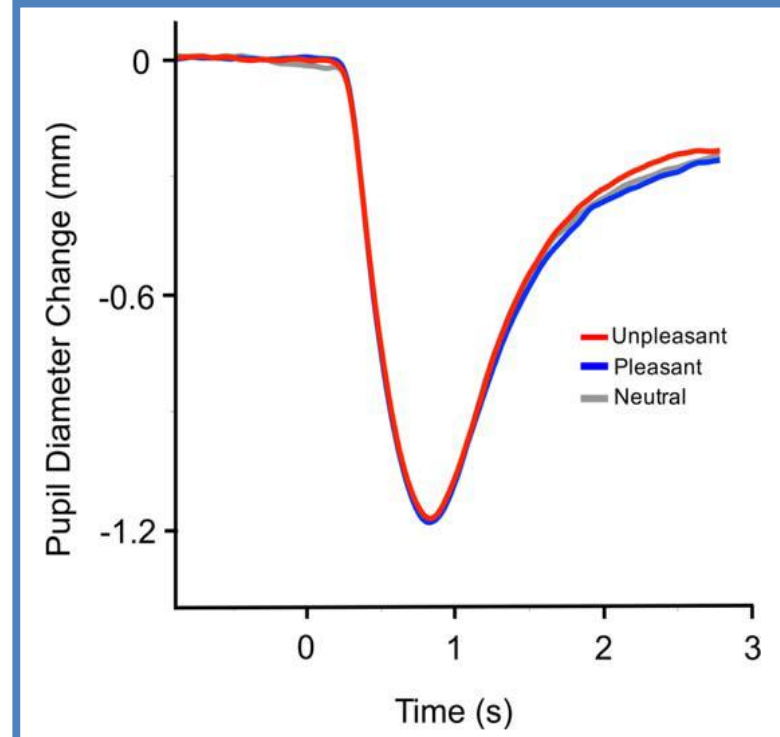

Fig 4. Pupil diameter change ( $\mathrm{mm})$ following the presentation of a light probe consisting of a brief change in screen illumination in the context of imagining either unpleasant, pleasant, or neutral scenes. Pupil diameter is shown deviated from a 1 -s preprobe baseline.

\section{Burnout}

We utilized the 22-item Maslach burnout inventory. ${ }^{84}$ This measure assesses three related but independent aspects of burnout. The questions were adapted to apply to pupils rather than recipients of care. Example items from each subscale are 'I feel emotionally drained from my work' (emotional exhaustion), 'I've become more callous towards people since I took this job' (depersonalization) and 'I have accomplished many worthwhile things in this job' (personal accomplishment). Items are measured on a seven-point scale ranging from $1=$ 'Never' to $7=$ 'Every day.' This measure has been used widely in samples of employees, and the three-factor structure has been supported ${ }^{10,85}$. Mean scores were calculated across items with higher scores denoting higher levels of emotional exhaustion, depersonalization and personal accomplishment (Emotional exhaustion [nine items: a $=0.98$, depersonalization [five items: $\mathrm{a}=0.78$ and personal accomplishment [eight items: $\mathrm{a}=0.91]$ ).

\section{Job satisfaction}

We utilized the Warr, Cook, and Wall's (1979) 15-item measure. ${ }^{86}$ This global measure assesses levels of satisfaction with extrinsic aspects of work (e.g., rate of pay and promotion opportunities), as well as intrinsic factors (e.g., variety, control, and recognition). This is one of the most commonly used measures of job satisfaction, and its unidimensionality has been confirmed. ${ }^{86,87}$ Responses are invited on a seven-point scale ranging from 1 = 'I'm extremely dissatisfied' to 7 


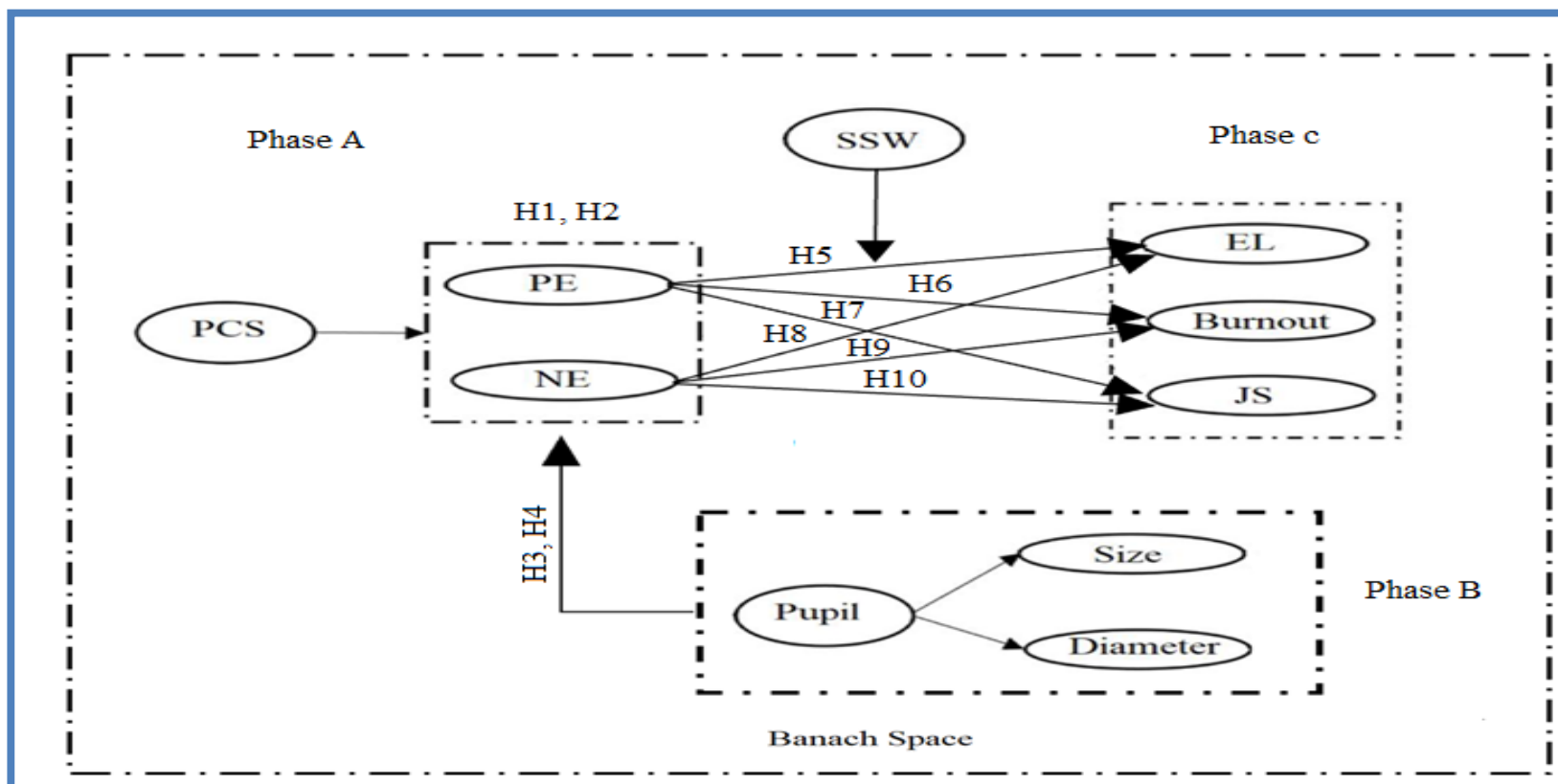

Fig 5. Hypostasized Research Model

= 'I'm extremely satisfied.' Mean scores were calculated across items with higher scores representing more job satisfaction $(\mathrm{a}=90)$.

\section{Social support}

We assessed Social support by an eight-item measure developed by Ybema and Smulders (2002). ${ }^{88}$ The measure assesses levels of support from different sources at work on a five-point scale ranging from $1=$ 'Not at all' to $5=$ 'A great deal.' Items include 'To what extent can you count on your immediate manager to listen to you when you need to talk about problems at work?' and 'To what extent can you count on your colleagues to help you with a difficult task at work?' This measure has been used in a large-scale study of the working population in the Netherlands that included employees. ${ }^{88}$ Principal component factor analysis confirmed the unidimensionality of this scale with a single factor accounting for $79 \%$ of the variance. Mean scores were calculated across items, with higher scores represent higher levels of workplace social support $(\mathrm{a}=92)$.

\section{Hypothesized Theoretical Model}

Figure 5 illustrates (a) the direction of the relationships of Psychology Cognition Science, Emotions "Positive and Negative"; and (b) Pupil "Size and Diameter" on Emotions "Positive and Negative"; and (c) Social Support in Workplace as a mediating variable on the relation between emotions " $P E, N E$ " and Emotional Labor, and Burnout and Job Satisfaction. PCS = Psychology Cognition Science, PE = Positive Emotion, $\mathrm{NE}=$ Negative Emotion, EL = Emotional Labor, JS = Job Satisfaction and SSW = Social Support in Workplace. This work has three-phase and the hypothesis will be reported to each phase. This is so important to consider all of the space in this research are based on "Banach Theory."

About behavior, what we do is "Asymptotic behavior of solutions of nonlinear delay difference equations in Banach spaces" according to Anna Kisiolek and Ireneusz Kubiaczyk (2005). ${ }^{111,113}$. In the second-order difference equation of the form was considered Eq. (7).

Authors give a condition when this equation has a solution, asymptotically equal to $c, c \in \mathbb{R}$.

\section{Hypothesis}

Phase A

H1. There is a positive relationship between PCS and PE. $\mathrm{H} 2$. There is a positive relationship between PCS and NE.

Phase B

H3. There is a positive relationship between Pupil size and "PE, NE."

H4. There is a positive relationship between Pupil diameter and " $P E, N E$."

Phase C

H5. PE has a positive relationship with EL trough considering SSW as a mediating role.

H6. PE has a positive relationship with Burnout trough considering SSW as a mediating role.

H7. PE has a positive relationship with JS trough considering SSW as a mediating role.

H8. NE has a positive relationship with EL trough considering SSW as a mediating role.

H9. NE has a positive relationship with Burnout trough considering SSW as a mediating role.

H10. NE has a positive relationship with JS trough, considering SSW as a mediating role. 
Social support, cognitive psychology and emotional process

Eur J Transl Myol 30 (3): xx1-x17, 2020

Table 1. Means, Standard Deviation and Inter-Correlations of variables

\begin{tabular}{|c|c|c|c|c|c|c|c|c|}
\hline & Mean (SD) & 1 & 2 & 3 & 4 & 5 & 6 & 7 \\
\hline Emotional Labor (EI) & $2.90(0.90)$ & 0.00 & & & & & & \\
\hline Emotional Exhaustion (EE) & $3.78(1.26)$ & $0.4 * * *$ & 0.00 & & & & & \\
\hline Depersonalization & $2.26(1.14)$ & $0.44 * * *$ & $0.58 * * *$ & 0.00 & & & & \\
\hline Personal Accomplishment (PA) & $3.93(1.63)$ & $0.10^{*}$ & $-0.11^{* *}$ & -0.07 & 0.00 & & & \\
\hline Job Satisfaction (JS) & $4.77(0.93)$ & $-0.37 * * *$ & $0.55 * * *$ & $-0.36 * * *$ & $0.18^{* * *}$ & 0.00 & & \\
\hline Workplace Social Support (WSS) & $3.83(0.90)$ & $-0.26 * * *$ & $-0.54 * * *$ & $-0.15 * * *$ & $0.10^{*}$ & $0.60 * * *$ & 0.00 & \\
\hline Job Experience (JE)/Years & $12.97(11.36)$ & $0.09 *$ & 0.02 & 0.03 & $0.36 * * *$ & $0.10 *$ & -0.06 & 0.00 \\
\hline
\end{tabular}

\section{Discussion}

The target sample comprised 1500 employees working in the banking sector or the manufacturing sector across China. The employee was accessed at their places of work and during training sessions. 628 completed questionnaires were returned. $74 \%$ of respondents were female, with a mean age of 36 years $(S D=10.5)$. The number of years of working experience ranged from 1 to 39 with a mean of 12.97 years $(S D=11.4)$. Zero-order correlations were used to examine relationships between variables. Hierarchical regression analysis was utilized to examine whether workplace social support moderated the relationship between emotional labor and the three components of burnout (emotional exhaustion, depersonalization, and personal accomplishment). Before conducting the regressions, residual plots were used to test normality, linearity, and equality of variances, with no violations being found. The procedure recommended by Baron and Kenny (1986) for detecting moderating effects was followed. Interaction terms were computed as the product of the centered scores. ${ }^{89}$ As differences between males and females have been found in the extent of emotional labor performed, ${ }^{49}$ gender was entered in Step 1 of each regression to control for its potential effects. This step also controlled for job experience as this was significantly correlated with emotional labor and two of the three burnout dimensions (see results section below). Emotional labor and social support were entered simultaneously in Step 2, with the two-way interaction term emotional labor $\times$ social support introduced in Step 3. A significant moderation effect would be found in Step 3 accounted for additional variance in any of the outcome variables. Table 1 provides details of the mean scores and standard deviations for all study variables. Also shown are intercorrelations between emotional labor, the four-strain outcomes (emotional exhaustion, depersonalization, personal accomplishment, and job satisfaction), social support and job experience. Significant positive associations were observed between emotional labor and both emotional exhaustion and depersonalization, and a negative association with job satisfaction. A weak positive relationship was found between emotional labor and feelings of personal accomplishment. Employees who reported higher levels of workplace social support tended to report less emotional labor, emotional exhaustion and depersonalization, and more personal accomplishment and job satisfaction. Length of experience in the employee role was positively related to emotional labor, in that employees with longer service tended to perform more emotional labor, but this association was only weak. The working experience was positively related to feelings of personal accomplishment and job satisfaction, but no significant relationships with emotional exhaustion and depersonalization were observed. Hierarchical regression analyses were conducted to examine whether workplace social support colleagues moderated the relationship between emotional labor and the strain outcomes utilized in the study. Details of the regressions are provided in Table 2 (only significant regressions are shown). Findings suggest that workplace social support might, to some extent, protect employees from the negative impact of emotional labor. Significant two-way interactions were found between emotional labor and support in predicting emotional exhaustion, feelings of personal accomplishment, and job satisfaction. For emotional exhaustion, gender and job experience entered in Step 1 of the regression failed to account for variance. The main effects of emotional labor ( $\beta=0.43, \mathrm{p}<0.001)$ and social support $(\beta=0.15, \mathrm{p}<$ 0.001 ) entered in Step 2 of the regression explained $23 \%$ of variance in emotional exhaustion. The two-way interaction entered in Step 3 accounted for an additional $2 \% \quad(\beta=0.92, \mathrm{p}<0.01)$. In predicting personal accomplishment, gender explained $3 \%$ of the variance ( $\beta=0.18, \mathrm{p}<0.001)$ and the main effects of emotional demands ( $\beta=0.43, \mathrm{p}<0.001$ ) and support ( $\beta=0.11, \mathrm{p}$ $<0.01$ ) accounted for a further $21 \%$. The two-way interaction explained an additional $1 \%(\beta=0.37, \mathrm{p}<$ $0.05)$. For job satisfaction, gender explained $3 \%$ of the variance $(\beta=0.16, \mathrm{p}<0.001)$ and the main effects of emotional demands ( $\beta=0.24, \mathrm{p}<0.001$ ) and support ( $\beta=0.55, \mathrm{p}<0.001)$ accounted for a further $42 \%$. When the two-way interaction was introduced in Step 3, a further $2 \%$ of the variance in job satisfaction was accounted for $(\beta=0.63, \mathrm{p}<0.01)$. 
Social support, cognitive psychology and emotional process

Eur J Transl Myol 30 (3): xx1-x17, 2020

Table 2. Hierarchical regressions showing emotional labor predicting outcome variables

\begin{tabular}{|c|c|c|c|}
\hline Predictors & $\begin{array}{l}\text { Emotional } \\
\text { exhaustion }\end{array}$ & $\begin{array}{c}\text { Personal } \\
\text { accomplishment }\end{array}$ & $\begin{array}{c}\text { Job } \\
\text { satisfaction }\end{array}$ \\
\hline Gender & 0.03 & $0.18 * * *$ & $-0.16 * * *$ \\
\hline Experience in Job Role & 0.01 & 0.00 & 0.07 \\
\hline Step $1 \mathbf{R}^{2}$ & 0.00 & $-0.03 * * *$ & $0.03 * * *$ \\
\hline Gender & 0.05 & $0.16 * * *$ & $-0.12 * * *$ \\
\hline Experience in Job Role & -0.05 & 0.05 & $0.18 * * *$ \\
\hline Emotional Labor & $0.43 * * *$ & $-0.42 * * *$ & $-0.24 * * *$ \\
\hline Social Support & $-0.15 * * *$ & $0.11 * *$ & $0.55 * * *$ \\
\hline Step 2 R $^{2}$ Change & $0.23 * * *$ & $-0.21 * * *$ & $0.42 * * *$ \\
\hline Gender & 0.05 & $0.17 * * *$ & $-0.12 * * *$ \\
\hline Experience in Job Role & -0.05 & 0.06 & $0.18 * * *$ \\
\hline Emotional Labor & $0.62 * * *$ & $-0.74 * * *$ & $-0.19 * *$ \\
\hline Social Support & $-0.12 * *$ & 0.16 & $0.63 * * *$ \\
\hline $\begin{array}{c}\text { Emotional Labor } \times \text { Social } \\
\text { Support }\end{array}$ & $-0.92 * *$ & $0.37 *$ & \\
\hline Step $3 \mathbf{R}^{2}$ Change & $0.02 * *$ & $0.01 *$ & $0.02 * *$ \\
\hline Total $\mathbf{R}^{2}$ & 0.25 & 0.25 & 0.49 \\
\hline \multicolumn{4}{|c|}{$* \mathrm{p}<0.05, * * \mathrm{p}<0.01, * * * \mathrm{p}<0.001$} \\
\hline
\end{tabular}

In line with previous research, the current study shows that large pupils are overall perceived more positively and small pupils more negatively. ${ }^{79-81}$ Possibly, because large pupils fit in the baby schema (children tend to have larger pupils than adults, as have good characters in cartoons), people associate large pupils with harmlessness. However, research has shown that children are as sensitive to the baby schema as adults, and like faces that fit into that scheme much better than ones that do not. ${ }^{90}$ Thus, those large pupils are consistent with the baby scheme is at least not the full explanation for why large pupils are liked so much. An alternative explanation is that people in positive compared to negative states do have actual large c.q. Small pupil sizes. Both sympathetic and parasympathetic inputs govern pupil size. Pupil dilation is typically seen in tasks requiring either physical (lifting weights) or mental effort, including tasks with a high working memory load. ${ }^{91}$ Moreover, emotional arousal, regardless of valence, is also reflected in the magnitude of pupillary dilation, ${ }^{92-94}$ and is associated with sympathetic activity and norepinephrine levels, elicited by the locus coeruleus. ${ }^{95}$ Yet, initial pupillary dilations and those driven from higher-order visual features are largely driven by the release of parasympathetic inhibition at the Edinger-Westphal nucleus. ${ }^{96}$. Pupillary constriction occurs to stimulus attributes such as the onset of color change, spatial structure, or coherent movement, ${ }^{96}$ but a general small pupil size can be indicative of fatigue as well. ${ }^{97}$ Thus, based on people's pupil size alone, it is hard to say anything meaningful about their state of mind and whether that is positive or negative. However, with extra contextual information, I would like to argue, it may be possible. In the context of social interaction, for instance, pupillary cues might be particularly meaningful. This study has extended knowledge of the type of stressors experienced by employees and the potential impact on well-being. The findings provide empirical support for previous observations that emotional labor is a fundamental aspect of their role that has potentially negative consequences for well-being. ${ }^{20,26}$. Evidence has also been provided that the emotional demands of teaching might have an adverse impact on job performance. Employees who reported more emotional labor were not only more emotionally exhausted and less satisfied with their work; they were also more likely to depersonalize their pupils. The employee may develop less sympathetic and more cynical attitudes towards their pupils over time as a self-protective strategy. The finding that emotional labor was positively related to job experience would support this proposition. Longitudinal studies are required to further elucidate the role played by emotional labor in the development of burnout in employees overtime, together with the impact of different coping strategies. Some evidence has been provided that the impact of emotional labor may not be wholly negative for employees. Several studies have found a negative association between sustained emotional labor and personal accomplishment that could be explained by increased feelings of negativity about the self and the job that are engendered by emotional exhaustion and depersonalization, ${ }^{56,98}$ However, the present research 
found that employees who performed more emotional labor tended to report higher rather than lower levels of personal accomplishment. Following the findings of a study of human service professionals conducted by Brotheridge and Grandey (2002), ${ }^{24}$ this suggests that fulfilling the emotional demands of training in work might boost feelings of competence and satisfaction with achievement. It should be noted, however, that the relationship between emotional labor and personal accomplishment was not robust, and the strong negative associations observed with job satisfaction contradicts this argument. The findings of this study suggest that employees who perform more emotional labor tend to experience lower levels of job satisfaction. Studies of service sector employees have found that emotional labor can reduce feelings of satisfaction with the job role by depleting emotional resources and engendering feelings of emotional inauthenticity. ${ }^{55,98}$. Nonetheless, as it has been suggested that employees consider emotional labor to be an intrinsic part of their work, ${ }^{62}$ positive associations between emotional labor and job satisfaction were anticipated. Further research is needed to examine the type of emotional demands that employees see as intrinsic to the job role (and therefore potentially a source of satisfaction), and those that are perceived to be less legitimate. Previous studies of employees have highlighted the positive impact of a supportive working climate on well-being. ${ }^{67}$ Similarly, the present study found significant main effects of workplace social support on the three dimensions of burnout and job satisfaction. This implies that enhancing social support from various sources will help employees manage the emotional labor of the job more effectively, protect them from burnout, and engender job satisfaction. The inverse association between social support and depersonalization also suggests that developing a supportive work environment is likely to enhance job performance by helping employees manage feelings of estrangement from the job role. In support of the buffering hypothesis ${ }^{64}$ evidence was also found that workplace social support might protect employees against the negative impact of emotional labor on well-being. The relationship between emotional labor and emotional exhaustion, personal accomplishment, and job satisfaction tended to be attenuated by social support. Although workplace support is clearly a protective factor in helping employees withstand the negative effects of emotional labor, an examination of the relative impact of different types of social support (such as informational, practical, appreciative and emotional: ${ }^{99}$ received from different sources (such as colleagues, managers, administrators and parents) would help elucidate this process. For some time, it has been argued that support is more likely to mitigate the effects of a stressor if the type of support received closely corresponds to the type of stressor. ${ }^{64}$ The recently developed 'triple-match' principle, ${ }^{100}$ extends this proposition by maintaining that a closer match occurs when the job stressor, resource, and type of strain are based on 'qualitatively similar dimensions.' Future research in educational settings might utilize this framework to examine the potential buffering effects of emotional support on the relationship between emotional labor and emotional exhaustion. The findings would have the potential to inform more precisely targeted interventions to help employees manage the emotional labor process more effectively. Interventions are required to mitigate the negative impact of emotional labor in the teaching profession and help employees enhance their emotion management skills. Little is yet known, however, about the type of interventions that might be successful in achieving these aims in the context of teaching, but some suggestions can be made. The importance of helping employees develop firm emotional boundaries between work and home and utilize effective recovery strategies has been emphasized; indeed, there is evidence that employees who are more adept at detaching emotionally from work have greater protection from the adverse impact of emotional labor. ${ }^{101}$ Evidence is also accumulating that emotional intelligence is an important personal resource that helps employees cope successfully with emotion work and helps build resilience to stress more generally. ${ }^{52,102,103}$ A study of employees recently conducted by Brackett, Palomera, Mojsa-Kaja, Reyes, Salovey $(2010)^{104}$ suggested that those who are better able to regulate their own emotional states, and those of others, experience stronger feelings of personal accomplishment and more job satisfaction. These findings suggest that training to enhance emotional competence might be beneficial in helping employees manage emotional labor and other types of the stressor. To conclude, this study shows that people associate positive faces with large pupil sizes and negative faces with small pupil sizes. This effect increased overage, which was especially related to older individuals drawing particularly smaller pupil sizes in the angry face than younger individuals. The fact that age is of influence here at all makes it most likely that real-world experiences are necessary to establish these associations. Further suggestions could be made based on studies of service sector employees. Mann (2004) $)^{105}$ recommends that policies and practices should be introduced to encourage the expression of emotion as a 'natural' part of the job. She further suggests that holistic programmes that encompass stress management interventions, debriefing, and the encouragement of 'healthy catharsis' are likely to be beneficial. The extent to which interventions that have been developed in other professional contexts would be successful in helping employees manage emotional labor is open to question. Interventions that encourage emotional expression may be particularly problematic in such environments. Hargreaves $(2000)^{20}$ has argued that successful emotion management in teaching tends to be perceived 'as largely a matter of personal disposition, moral commitment or private virtue,' rather than a skill that can be enhanced. Moreover, it has been suggested that the ethic of emotional control within the profession 
might be so pervasive that employees are reluctant to discuss their 'true' feelings. ${ }^{21}$ This may be particularly the case for employees who are more experienced and who may fear a loss of credibility if they share what they consider to be 'inappropriate' emotions with colleagues. Nonetheless, the findings of the present study suggest that interventions designed to enhance social support from managers and colleagues might be particularly beneficial in minimizing the negative impact of emotional labor on well-being. Enhancing staff support networks to increase group cohesion and the provision of emotional mentoring might be useful. Studies have found reciprocal peer coaching, where pairs of employees work together to reflect on practice and provide mutual support, can help employees develop their knowledge, skills, attitudes, and values. ${ }^{106}$ Peer coaching techniques might, therefore, be particularly appropriate in facilitating healthy catharsis and helping employees develop more adaptive emotional management skills. Although this study has extended knowledge of the emotional labor inherent in teaching and its potential impact, it has several limitations. Firstly, as the study is cross-sectional, the postulated relationships cannot be interpreted causally. It is plausible that employees who experience burnout and job dissatisfaction might perceive more emotional demands arising from their work rather than vice versa. Longitudinal studies would validate the causality of the observed relationships. Secondly, the data obtained in this study were derived from self-report questionnaires. Although there is a fundamental difficulty in measuring emotion-related constructs more objectively, the risk of common method variance is acknowledged. Thirdly, this study obtained assessments of emotional labor through retrospective, aggregated reports. While such methods can highlight relationships between aspects of emotional labor and strain, little insight is gained into the type of situations that are considered to be particularly emotionally demanding.

Daily diaries and experiential sampling methodology have the potential to capture specific work events that are considered emotionally demanding, how employees cope with such events, and the impact on well-being through time. ${ }^{107,108}$

\section{List of acronyms}

BOLD - Blood Oxygenation Level-Dependent

EL - Emotional Labor

JS - Job Satisfaction

NE - Negative Emotion

PCS - Psychology Cognition Science

PE - Positive Emotion

SD - Standard Deviation

SSW - Social Support in Workplace

\section{Appendix}

We give necessary and sufficient conditions for the existence of solutions.
Let $\mathrm{f}$ be the function from $\mathrm{X}$ to $\mathrm{X},\left(\mathrm{p}_{\mathrm{n}}\right),\left(\mathrm{r}_{\mathrm{n}}\right)$ sequences of real numbers, and $\left(h_{n}\right)$ a sequence in Banach space.

Let $\mathrm{D}$ be a nonempty, closed, convex, and bounded subset of Banach spaces. The following fixed-point theorem will prove our result.

Equation 8. ${ }^{109}$ Let D be a nonempty, closed, convex, and bounded subset of Banach spaces.

Let $\mathrm{F}: \mathrm{D} \rightarrow \mathrm{D}$ be a continuous mapping, which is condensing concerning the measure of noncompactness $\alpha$ :

$\alpha(F(V)) \leq L \alpha(V), \quad L \prec 1$.

Then $\mathrm{F}$ has a fixed point, where $\alpha$ is the Kuratowski's measure of noncompactness.

Eq (9). Let $V \subset \mathbb{C}\left(N^{+}, X\right)$ be a family of functions. Then

$$
\alpha(V)=\alpha\left(V\left(N^{+}\right)\right)=\operatorname{Sup}\left\{a(V(i)): i \in N^{+}\right\}
$$

Where $\alpha(\mathrm{V})$ denotes the measure of noncompactness in. A theorem similar to Theorem 8 was proved by Arino et al. (1984), ${ }^{110}$ see also I. Kubiaczyk, $1995 ;{ }^{111}$ A. R. Mitchell and C. Smith, 1977, ${ }^{114}$ when $f$ is weakly-weakly sequentially continuous, that is, if $x_{n} \stackrel{w}{\rightarrow} x_{0}$, then $f\left(x_{n}\right) \stackrel{w}{\rightarrow} f\left(x_{0}\right)$ for each sequence $\left(\mathrm{x}_{\mathrm{n}}\right)$, and instead of $\alpha$ we used $\beta$-weak measure of noncompactness.

Theorem 10. Let $\mathrm{f}: \mathrm{X} \rightarrow \mathrm{X}$ be the bounded and continuous function.

Let

$t=\sum_{n=1}^{\infty}\left(\sum_{j=0}^{n-1} \frac{1}{r_{j}}\right)\left|p_{n}\right| \prec \infty$,

$\sum_{n=1}^{\infty}\left(\sum_{j=0}^{n-1} \frac{1}{r_{j}}\right)\left\|h_{n}\right\| \prec \infty$.

Moreover,

$a(f(V)) \leq k a(V)$

Where $\mathrm{kt}<1$.

Then for every, $a, b \in \mathbb{R}$ there exists a solution $\left(\mathrm{x}_{\mathrm{n}}\right)$ of (Eq. 3) Which possesses the asymptotic behavior

$\left\|x_{n}-a \sum_{j=0}^{n-1} \frac{1}{r_{j}}+b\right\|=0(1)$

Proof. Let $a, b \in X$. There exists a constant $\mathrm{M}>1$ such that $\|f(t)\| \prec M$ for each $\mathrm{t} \in \mathrm{X}$.

Assume that

$k_{n}=\left|p_{n}\right|+\left\|h_{n}\right\| \quad n \in N$,

$l_{n}=\frac{1}{r_{n}} \sum_{j=n+1}^{\infty} k_{j}$

From (Eq. 10) we have 


$$
\begin{aligned}
& \sum_{n=1}^{\infty}\left(\sum_{j=0}^{n-1} \frac{1}{r_{j}}\right)\left|p_{n}\right|+\sum_{n=1}^{\infty}\left(\sum_{j=0}^{n-1} \frac{1}{r_{j}}\right)\left\|h_{n}\right\| \\
& =\sum_{n=1}^{\infty}\left(\sum_{j=0}^{n-1} \frac{1}{r_{j}}\right)\left(\left|p_{n}\right|+\left\|h_{n}\right\|\right)=\sum_{n=1}^{\infty}\left(\sum_{j=0}^{n-1} \frac{1}{r_{j}}\right) k_{n} \\
& =k_{1} \cdot \frac{1}{r_{0}}+k_{2} \cdot\left(\frac{1}{r_{0}}+\frac{1}{r_{1}}\right)+k_{3} \cdot\left(\frac{1}{r_{0}}+\frac{1}{r_{1}}+\frac{1}{r_{2}}\right)+\ldots \\
& =\frac{1}{r_{0}}\left(k_{1}+k_{2}+k_{3}+\ldots\right)+\frac{1}{r_{1}}\left(k_{2}+k_{3}+\ldots\right)+\frac{1}{r_{2}}\left(k_{3}+\ldots\right) \\
& =\sum_{n=1}^{\infty} \frac{1}{r_{n-1}} \sum_{j=n}^{\infty} k_{j}=\sum_{n=1}^{\infty} l_{n-1 .}
\end{aligned}
$$

So the series $\sum_{n=1}^{\infty} l_{n}$ is convergent.

Let $z_{n}=\sum_{j=n}^{\infty} l_{j}$ for $n \in N$.

Define the operator $\mathrm{T}: \mathrm{D} \rightarrow \mathrm{K}$, where

$D=\left\{y=\left(y_{1}, y_{2}, y_{3}, \ldots\right),\left\|y_{n}\right\| \leq M z_{n}\right\}, \quad n \in N$

$K=\left\{y=\left(y_{1}, y_{2}, y_{3}, \ldots\right),\left\|y_{n}-\left(a \sum_{j=0}^{n-1} \frac{1}{r_{j}}+b\right)\right\| \leq M z_{n}\right\}, n \in N$.

For $\mathrm{x} \in \mathrm{D}$ and $\mathrm{n} \in \mathrm{N}$ we have

$(T x)_{n}= \begin{cases}a \sum_{j=0}^{n-1} \frac{1}{r_{j}}+b, & n \leq m, \\ a \sum_{j=0}^{n-1} \frac{1}{r_{j}}+b-\sum_{j=n}^{\infty} \frac{1}{r_{j}} \sum_{j=j+1}^{\infty}\left(p_{i} f\left(x_{i-k}\right)-h_{i}\right), & n \succ M .\end{cases}$

For $\mathrm{n}>\mathrm{m}$ we have

$\left\|(T x)_{n}-\left(a \sum_{j=0}^{n-1} \frac{1}{r_{j}}+b\right)\right\|$

$$
\begin{aligned}
& =\left\|a \sum_{j=0}^{n-1} \frac{1}{r_{j}}+b-\sum_{j=n}^{\infty} \frac{1}{r_{j}} \sum_{i=j+1}^{\infty}\left(p_{i} f\left(x_{i-k}\right)-h_{i}\right)-a \sum_{j=0}^{n-1} \frac{1}{r_{j}}-b\right\| \\
& =\left\|\sum_{j=n}^{\infty} \frac{1}{r_{j}} \sum_{i=j+1}^{\infty}\left(p_{i} f\left(x_{i-k}\right)-h_{i}\right)\right\| \\
& \leq \sum_{j=n}^{\infty} \frac{1}{r_{j}} \sum_{i=j+1}^{\infty}\left\|\left(p_{i} f\left(x_{i-k}\right)-h_{i}\right)\right\| \leq \sum_{j=n}^{\infty} \frac{1}{r_{j}} \sum_{i=j+1}^{\infty}\left(\left\|p_{i} f\left(x_{i-k}\right)\right\|-\left\|h_{i}\right\|\right) \\
& \leq \sum_{j=n}^{\infty} \frac{1}{r_{j}} \sum_{i=j+1}^{\infty}\left(\left\|h_{i}\right\|+M\left|p_{i}\right|\right) \leq \sum_{j=n}^{\infty} \frac{1}{r_{j}} \sum_{i=j+1}^{\infty} M k_{i} \leq M \sum_{j=n}^{\infty} l_{j}=M z_{n} .
\end{aligned}
$$

So, the operator $\mathrm{T}: \mathrm{D} \rightarrow \mathrm{K}$ and the continuity of $\mathrm{f}, \mathrm{T}$ is continuous.

Now, we will prove that $\mathrm{T}$ satisfies condition (8) of Theorem (8).

Let $\mathrm{V} \subset \mathrm{D}$, where $\mathrm{V}=\left\{\mathrm{v}: \mathrm{v}=\left(\mathrm{v}_{1}, \mathrm{v}_{2}, \ldots\right)\right\}$ and $\mathrm{T}(\mathrm{V})=$ $\{\mathrm{T}(\mathrm{v}): \mathrm{v} \in \mathrm{V}\}$.

Let $\mathrm{V}_{\mathrm{k}}=\left\{\mathrm{vk}: \mathrm{v} \in \mathrm{V}, \mathrm{v}=\left(\mathrm{v}_{1}, \mathrm{v}_{2}, \ldots, \mathrm{v}_{\mathrm{k}}, \ldots\right)\right\}$.

For $\mathrm{n} \leq \mathrm{m}$ we obtain

$$
a(T(V))=a\left(a \sum_{j=0}^{n-1} \frac{1}{r_{j}}+b\right)=0 \text {. }
$$

For $\mathrm{n}>\mathrm{m}$ we have

$$
\begin{aligned}
& a(T(V))=\underset{n}{\operatorname{Sup} a}\left(a \sum_{j=0}^{n-1} \frac{1}{r_{j}}+b-\sum_{j=n}^{\infty} \frac{1}{r_{j}} \sum_{i=j+1}^{\infty}\left(p_{i} f\left(V_{n}\right)-h_{i}\right)\right) \\
& \leq \underset{n}{\operatorname{Sup} a}\left[a\left(a \sum_{j=0}^{n-1} \frac{1}{r_{j}}+b\right)+a\left(\sum_{j=n}^{\infty} \frac{1}{r_{j}} \sum_{i=j+1}^{\infty}\left(p_{i} f\left(V_{n}\right)-h_{i}\right)\right)\right] \\
& \leq \underset{n}{\operatorname{Sup} a}\left[\sum_{j=n}^{\infty} \frac{1}{r_{j}} \sum_{i=j+1}^{\infty} p_{i} f\left(V_{n}\right)+\sum_{j=n}^{\infty} \frac{1}{r_{j}} \sum_{i=j+1}^{\infty} h_{i}\right] \\
& \leq \operatorname{Sup}_{n}\left(\sum_{j=n}^{\infty} \frac{1}{r_{j}} \sum_{i=j+1}^{\infty} a\left(p_{i} f\left(V_{n}\right)\right)\right) \leq \sum_{j=n}^{\infty} \frac{1}{r_{j}} \sum_{i=j+1}^{\infty}\left|p_{i}\right| a\left(f\left(V_{n}\right)\right) .
\end{aligned}
$$

Using the inequality

$$
a(f(V)) \leq k a(V)
$$

We obtain that

$$
a(T(V)) \leq k a(V) \sum_{j=n}^{\infty} \frac{1}{r_{j}} \sum_{i=j=1}^{\infty}\left|p_{i}\right| \leq k a(V) \text {. }
$$

By Theorem $8 \mathrm{~T}$ has a fixed point, and by the definition of $\mathrm{T}$ the solution $\mathrm{x}=\left(\mathrm{x}_{\mathrm{n}}\right)$ satisfies the condition

$\left\|x_{n}-a \sum_{j=0}^{n-1} \frac{1}{r_{j}}+b\right\|=0(1)$

This completes the proof of the theorem.

Because we can extend Theorem (8) as in O. Arino, S. Gautier, and J.-P. Penot, 1984; ${ }^{110}$ I. Kubiaczyk, 1995, ${ }^{111}$ so similar to Theorem (9), we can prove the following theorem.

Theorem, (10). Let $\mathrm{f}: \mathrm{X} \rightarrow \mathrm{X}$ be the bounded and weakweakly continuous function.

Let

$$
\begin{aligned}
& t=\sum_{n=1}^{\infty}\left(\sum_{j=0}^{n-1} \frac{1}{r_{j}}\right)\left|p_{n}\right| \prec \infty, \\
& \sum_{n=1}^{\infty}\left(\sum_{j=0}^{n-1} \frac{1}{r_{j}}\right)\left\|h_{n}\right\| \prec \infty .
\end{aligned}
$$

And kt $<1$. Moreover

$$
\beta(f(V)) \leq k \beta(V)
$$

Then for every, $a, b \in \mathbb{R}$ there exists a solution $\left(\mathrm{x}_{\mathrm{n}}\right)$ of (3) which possesses the asymptotic behavior

$$
\left\|x_{n}-a \sum_{j=0}^{n-1} \frac{1}{r_{j}}+b\right\|=0(1)
$$

Remark (Eq. 12). Observe that the class of continuous functions is different than the class of weakly-weakly sequentially continuous functions and weakly-weakly continuous functions. There exist many important examples of mappings that are weakly sequentially continuous but not weakly continuous. The strong relationship between weak and weak sequential continuity of mappings is studied in (J. M. Ball, 1975). ${ }^{116}$

\section{Authors contributions}

All authors equally contributed to the manuscript.

\section{Acknowledgments}

Results presented are significantly connected with the Ph.D. dissertation of Mohammad Heydari, which was written at the Nanjing University of Science and Technology entitled: "A Cognitive Basis Perceived Corruption and Attitudes Towards Entrepreneurial Intention" Supervisor: Professor Zhou Xiaohu, School of Economics and Management, Nanjing University of Science and Technology, Nanjing, Jiangsu, China. 
For more information about this dissertation, you can contact mohammad_heydari@njust.edu.cn and njustzxh@njust.edu.cn. There are several questions contained in this paper, which identify the purpose of further research. Also, we mention that this paper is the result of ten years of research in different countries on "Human and Organizational Behavior".

\section{Funding}

None

\section{Conflict of Interest}

The authors declare no competing interests.

\section{Ethical Publication Statement}

We confirm that we have read the Journal's position on issues involved in ethical publication and affirm that this report is consistent with those guidelines.

\section{Corresponding Author}

Zhou Xiaohu, School of Economics and Management, Nanjing University of Science and Technology, Nanjing, China. Phone +8613912969615

ORCID iD: 0000-0002-9811-3999

E-mail: njustzxh@njust.edu.cn

E-mails and ORCID iD of co-authors

Mohammad Heydari:

Mohammad_Heydari@njust.edu.cn

ORCID iD: 0000-0003-3942-2107

Mahdiye Saeidi: mahdisan57@yahoo.com

Kin Keung Lai: mskklai@outlook.com

ORCID iD: 0000-0003-0014-2095

Yufan Shang:yfshang@mail.xjtu.edu.cn

ZhengYuxi:xyzzoey@126.com

\section{References}

1. Hess EH. The role of pupil size in communication. Sci Am 1975; 233:110-9.

2. Johnson S, Cooper C, Cartwright $\mathrm{S}$, et al. The experience of work-related stress across occupations. J Managerial Ppsychol 2005: 20:17818

3. Jones J, Huxtable C, Hodgson J, et al. Self-reported work-related illness in 2001/02: Results from a household survey. Health and Safety Executive 2003.

4. Kyriacou C. Stress-busting for teachers. Nelson Thornes 2000.

5. Clunies-Ross P, Little E, Kienhuis M. Self-reported and actual use of proactive and reactive classroom management strategies and their relationship with teacher stress and student behaviour. Educat Psychol 2008; 28:693-710.

6. Hastings RP, Bham MS. The relationship between student behaviour patterns and teacher burnout. School Psychol Int 2003; 24:115-27.
7. Lewis R. Teachers coping with the stress of classroom discipline. Social Psychol Educat 1999; 3:155-71.

8. Maslach, C., \& Leiter, M. Teacher burnout: A research agenda. In R. Vandenberg \& A. Huberman (Eds.), Understanding and Preventing Teacher Burnout (pp. 295-303). Cambridge: Cambridge University Press. 1999.

9. Burke RJ, Greenglass E. A longitudinal study of psychological burnout in teachers. Human Relations 1995; 48:187-202.

10. Byrne BM. Burnout: Investigating the impact of background variables for elementary, intermediate, secondary, and university educators. Teach Teacher Educat 1991; 7:197-209.

11. Griva K, Joekes K. UK teachers under stress: Can we predict wellness on the basis of characteristics of the teaching job? Psychol Health 2003; 18:45771.

12. Kyriacou C. Teacher stress: Directions for future research. Educat Rev 2001; 53:27-35.

13. Pithers R, Soden R. Scottish and Australian teacher stress and strain: a comparative study. British J Educat Psychol 1998; 68:269-79.

14. Cooper C, Travers C. Teachers under pressure: Stress in the teaching profession: Routledge; 2012.

15. 15. Unterbrink T, Hack A, Pfeifer R, et al. Burnout and effort-reward-imbalance in a sample of 949 German teachers. Int Arch Occupat Envir Health 2007;80:433-41.

16. Van Dick R, Wagner U. Stress and strain in teaching: A structural equation approach. British J Educat Psychol 2001; 71:243-59.

17. Zapf D. Emotion work and psychological wellbeing: A review of the literature and some conceptual considerations. Human Res Manag Rev 2002; 12:237-68.

18. Fried RL. The passionate teacher: A practical guide: Beacon Press 2001.

19. Brennan K. The managed teacher: Emotional labour, education, and technology. Educat Insights 2006; 10:55-65.

20. Hargreaves A. Mixed emotions: Teachers' perceptions of their interactions with students. Teach Teacher Education 2000; 16:811-26.

21. Beatty BR. The emotions of educational leadership: Breaking the silence. Int J Leadership Educat 2000; 3:331-57.

22. Morris JA, Feldman DC. The dimensions, antecedents, and consequences of emotional labor. Acad Manag Rev 1996; 21:986-1010.

23. Hochschild AR. The managed heart. Berkeley. CA: University of California Press 1983.

24. Brotheridge CM, Grandey AA. Emotional labor and burnout: Comparing two perspectives of "people work”. J Vocational Behavior 2002; 60:17-39. 
25. Chang M-L. An appraisal perspective of teacher burnout: Examining the emotional work of teachers. Educational Psychol Rev 2009; 21:193-218.

26. Sutton RE. Teachers' emotions and classroom effectiveness: Implications from recent research. The Clearing House 2005; 78:229-34.

27. Winograd K. The Functions of Teacher Emotions: The Good, the Bad, and the Ugly. Teach College Record 2003; 105:1641-73.

28. Ogbonna E, Harris LC. Work intensification and emotional labour among UK university lecturers: An exploratory study. Organization Studies 2004; 25:1185-203.

29. Zhang Q, Zhu W. Exploring emotion in teaching: Emotional labor, burnout, and satisfaction in Chinese higher education. Communicat Educat 2008; 57:105-22.

30. Philipp A, Schüpbach H. Longitudinal effects of emotional labour on emotional exhaustion and dedication of teachers. J Occupational Health Psychol 2010; 15:494.

31. Butler EA, Lee TL, Gross JJ. Emotion regulation and culture: Are the social consequences of emotion suppression culture-specific? Emotion 2007;7:30.

32. Ferrari V, De Cesarei A, Mastria S, et al. Novelty and emotion: Pupillary and cortical responses during viewing of natural scenes. Biological Psychol 2016; 113:75-82.

33. Henderson RR, Bradley MM, Lang PJ. Modulation of the initial light reflex during affective picture viewing. Psychophysiol 2014;51(9):815-8.

34. Snowden RJ, O'Farrell KR, Burley D, et al. The pupil's response to affective pictures: Role of image duration, habituation, and viewing mode. Psychophysiol 2016; 53:1217-23.

35. Partala T, Surakka V. Pupil size variation as an indication of affective processing. Intl J HumanComputer Stud 2003; 59:185-98.

36. Bitsios P, Szabadi E, Bradshaw C. The fearinhibited light reflex: importance of the anticipation of an aversive event. Int J Psychophysiol 2004; 52:87-95.

37. Lang PJ, McTeague LM, Bradley MM. RDoC, DSM, and the reflex physiology of fear: A biodimensional analysis of the anxiety disorders spectrum. Psychophysiol 2016; 53:336-47.

38. Wangelin BC, Tuerk PW. Taking the pulse of prolonged exposure therapy: Physiological reactivity to trauma imagery as an objective measure of treatment response. Depression Anxiety 2015; 32:927-34.

39. Foa E, Hembree E, Rothbaum BO. Prolonged exposure therapy for PTSD: Emotional processing of traumatic experiences therapist guide: Oxford University Press 2007.

40. Lang PJ, Melamed BG, Hart J. A psychophysiological analysis of fear modification using an automated desensitization procedure. J Abnormal Psychol 1970; 76:220.

41. Henderson RR, Bradley MM, Mastria S, e al. editors. Speaking, imagining, and emotional reactivity. Psychophysiology WILEYBLACKWELL 111 River ST, Hoboken 070305774, NJ USA.2013

42. Costa VD, Lang PJ, Sabatinelli D, et al. Emotional imagery: assessing pleasure and arousal in the brain's reward circuitry. Human Brain Mapp 2010; 31:1446-57.

43. Vrana SR, Lang PJ. Fear imagery and the startleprobe reflex. Journal of abnormal psychology 1990; 99:189.

44. Steinhauer SR, Condray R, Pless ML. Pharmacological isolation of cognitive components influencing the pupillary light reflex. J Ophthalmol 2015;2015.

45. Sauseng P, Klimesch W, Schabus M, et al. Frontoparietal EEG coherence in theta and upper alpha reflect central executive functions of working memory. Int J Psychophysiol 2005; 57:97-103.

46. Sabatinelli D, Lang PJ, Bradley MM, et al. The neural basis of narrative imagery: emotion and action. Progress Brain Res 2006; 156:93-103.

47. Steinhauer SR, Siegle GJ, Condray R, et al. Sympathetic and parasympathetic innervation of pupillary dilation during sustained processing. Int $\mathbf{J}$ Psychophysiol 2004; 52:77-86.

48. Bradley MM, Sapigao RG, Lang PJ. Sympathetic ANS modulation of pupil diameter in emotional scene perception: Effects of hedonic content, brightness, and contrast. Psychophysiol 2017; 54:1419-35.

49. Grandey AA. Emotional regulation in the workplace: A new way to conceptualize emotional labor. J Occupational Health Psychol 2000; 5:95.

50. Goldberg LS, Grandey AA. Display rules versus display autonomy: emotion regulation, emotional exhaustion, and task performance in a call center simulation. J Occupational Health Psychol 2007; $12: 301$.

51. Kruml SM, Geddes D. Catching fire without burning out: Is there an ideal way to perform emotional labor. Emotions in the workplace: Res Theory Practice 2000:177-88.

52. Mikolajczak M, Menil C, Luminet O. Explaining the protective effect of trait emotional intelligence regarding occupational stress: Exploration of emotional labour processes. J Res Personality 2007; 41:1107-17.

53. Brouwers A, Tomic W. A longitudinal study of teacher burnout and perceived self-efficacy in classroom management. Teach Teacher Education 2000; 16:239-53.

54. Schaufeli W, Enzmann D. The burnout companion to study and practice: A critical analysis: CRC press 1998. 
55. Abraham R. Emotional dissonance in organizations: Antecedents, consequences, and moderators. Genetic, social, and general Psychology. Monographs 1998; 124:229.

56. Pugliesi K. The consequences of emotional labor: Effects on work stress, job satisfaction, and wellbeing. Motivation Emotion 1999; 23:125-54.

57. Adelmann, P. K. Emotional labor as a potential source of job stress. In S. L. Sauter \& L. R. Murphy (Eds.), Organizational risk factors for job stress (p. 371-381). American Psychological Association. 1995.

58. Ashforth BE, Humphrey RH. Emotional labor in service roles: The influence of identity. Acad Manag Rev 1993; 18:88-115.

59. Wharton AS. The affective consequences of service work: Managing emotions on the job. Work and occupations. Int Sociol J 1993; 20:205-32.

60. Bolton SC, Boyd C. Trolley dolly or skilled emotion manager? Moving on from Hochschild's managed heart. Work, Employment Society 2003;17:289-308.

61. Rafaeli A, Worline M. Individual emotion in work organizations. Social Sci information 2001; 40:95123.

62. Sutton RE. Emotional regulation goals and strategies of teachers. Social Psychol Education 2004; 7:379-98.

63. Jones F, Bright J, Clow A. Stress: Myth, theory and research. Pearson Education 2001.

64. Cohen S, Wills TA. Stress, social support, and the buffering hypothesis. Psychol Bulletin 1985; 98:310.

65. Beehr TA, Jex SM, Stacy BA, e al. Work stressors and coworker support as predictors of individual strain and job performance. J Organizat Beh 2000;21:391-405.

66. Zellars KL, Perrewé PL. Affective personality and the content of emotional social support: coping in organizations. J Applied Psychol 2001; 86:459.

67. Greenglass ER, Burke RJ, Konarski R. The impact of social support on the development of burnout in teachers: Examination of a model. Work Stress 1997; 11:267-78.

68. Chan DW. Stress, self-efficacy, social support, and psychological distress among prospective Chinese teachers in Hong Kong. Educational Psychol 2002; 22:557-69.

69. Duke AB, Goodman JM, Treadway DC, e al. Perceived organizational support as a moderator of emotional labor/outcomes relationships. J Applied Social Psychol 2009; 39:1013-34.

70. Deery S, Iverson R, Walsh J. Work relationships in telephone call centres: Understanding emotional exhaustion and employee withdrawal. J Manag Studies 2002; 39:471-96.
71. Bolton SC. 'Emotion Here, Emotion There, Emotional Organisations Everywhere'. Critical Perspect Account 2000; 11:155-71.

72. Agarwal RP. Difference equations and inequalities: theory, methods, and applications: CRC Press 2000.

73. Dawidowski M, Kubiaczyk I, Morchalo J. A discrete boundary value problem in Banach spaces. Glasnik Matematički 2001; 36:233-9.

74. Drozdowicz A, Popenda J. Asymptotic behavior of the solutions of the second order difference equation. Proceed Am Mathemat Soc 1987:135-40.

75. Migda M, Migda J. Asymptotic properties of the solutions of the second order difference equation. Arch Mathematicum 1998; 34:467-76.

76. Migda M. Asymptotic behaviour of solutions of nonlinear delay difference equations. Fasciculi Mathematici 2001:57-62.

77. Kret ME, De Dreu CK. Pupil-mimicry conditions trust in partners: Moderation by oxytocin and group membership. Proceed Royal Society B: Biological Sci 2017; 284:20162554.

78. Hess EH. Attitude and pupil size. Sci Am 1965; 212:46-55

79. Amemiya S, Ohtomo K. Effect of the observed pupil size on the amygdala of the beholders. Social Cog Affect Neurosci 2012; 7:332-41.

80. Demos KE, Kelley WM, Ryan SL, e al. Human amygdala sensitivity to the pupil size of others. Cerebral Cortex 2008;18:2729-34.

81. Harrison NA, Singer T, Rotshtein P, e al. Pupillary contagion: central mechanisms engaged in sadness processing. Social Cog Affect Neurosci 2006; 1:517.

82. Harrison NA, Wilson CE, Critchley HD. Processing of observed pupil size modulates perception of sadness and predicts empathy. Emotion 2007; 7:724.

83. Zapf D, Seifert C, Schmutte B, et al. Emotion work and job stressors and their effects on burnout. Psychol Health 2001; 16:527-45.

84. Maslach C, Jackson SE, Leiter MP, et al. Maslach burnout inventory: Consulting psychologists press Palo Alto, CA 1986.

85. Worley JA, Vassar M, Wheeler DL, et al. Factor structure of scores from the Maslach Burnout Inventory: A review and meta-analysis of 45 exploratory and confirmatory factor-analytic studies. Educat Psychol Measur 2008; 68:797-823.

86. Warr P, Cook J, Wall T. Scales for the measurement of some work attitudes and aspects of psychological well-being. J Occupational Psychol 1979; 52:12948.

87. Stride C, Wall TD, Catley N. Measures of job satisfaction, organisational commitment, mental health and job-related well-being: a benchmarking manual: John Wiley \& Sons 2008. 
88. Ybema JF, Smulders P. Emotionele belasting en de noodzaak tot het verbergen van emoties op het werk. Gedrag en Organisatie 2002.

89. Baron RM, Kenny DA. The moderator-mediator variable distinction in social psychological research: Conceptual, strategic, and statistical considerations. J Personality Soc Psychol 1986;51:1173.

90. Borgi M, Cogliati-Dezza I, Brelsford V, et al. Baby schema in human and animal faces induces cuteness perception and gaze allocation in children. Fron Psychol 2014; 5:411.

91. Kahneman D, Beatty J. Pupil diameter and load on memory. Science 1966;154(3756):1583-5.

92. Bradley MM, Miccoli L, Escrig MA, e al. The pupil as a measure of emotional arousal and autonomic activation. Psychophysiol 2008; 45:602-7.

93. Hess EH, Polt JM. Pupil size as related to interest value of visual stimuli. Sci 1960; 132:349-50.

94. Kret ME, Roelofs K, Stekelenburg J, et al. Emotional signals from faces, bodies and scenes influence observers' face expressions, fixations and pupil-size. Fron Human Neurosci 2013; 7:810.

95. Joshi S, Li Y, Kalwani RM, et al. Relationships between pupil diameter and neuronal activity in the locus coeruleus, colliculi, and cingulate cortex. Neuron 2016; 89:221-34.

96. Barbur JL. Learning from the pupil-studies of basic mechanisms and clinical applications. Visual Neurosc 2004; 1:641-56.

97. Morad Y, Lemberg H, Yofe N, et al. Pupillography as an objective indicator of fatigue. Current Eye Res 2000; 21:535-42.

98. Zapf D, Vogt C, Seifert C, et al. Emotion work as a source of stress: The concept and development of an instrument. European J Work Organizational Psychol 1999; 8:371-400.

99. Prins J, Hoekstra-Weebers J, Gazendam-Donofrio $\mathrm{S}$, et al. The role of social support in burnout among Dutch medical residents. Psychol Health Med 2007; 12:1-6.

100. Chrisopoulos S, Dollard MF, Winefield AH, et al. Increasing the probability of finding an interaction in work stress research: A two-wave longitudinal test of the triple-match principle. J Occupational Organizational Psychol 2010; 83:17-37.

101. Sonnentag S, Kuttler I, Fritz C. Job stressors, emotional exhaustion, and need for recovery: A multi-source study on the benefits of psychological detachment. J Vocational Beh 2010; 76:355-65.

102. Giardini A, Frese M. Reducing the negative effects of emotion work in service occupations: emotional competence as a psychological resource. J Occupational Health Psychol 2006; 11:63.

103. Kinman G, Grant L. Exploring stress resilience in trainee social workers: The role of emotional and social competencies. British J Social Work 2010; 41:261-75.

104. Brackett MA, Palomera R, Mojsa-Kaja J, et al. Emotion-regulation ability, burnout, and job satisfaction among British secondary-school teachers. Psychol Schools 2010; 47:406-17.

105. Mann S. 'People-work': emotion management, stress and coping. British J Guidance Counsel 2004; 32:205-21.

106. Zwart RC, Wubbels T, Bergen TC, et al. Experienced teacher learning within the context of reciprocal peer coaching. Teach Teaching: Theory Practice 2007; 13:165-87.

107. Grandey AA, Tam AP, Brauburger AL. Affective states and traits in the workplace: Diary and survey data from young workers. Motivation Emotion 2002; 26:31-55.

108. Totterdell P, Holman D. Emotion regulation in customer service roles: Testing a model of emotional labor. J Occupational Health Psychol 2003;8:55.

109. Darbo G. Punti uniti in trasformazioni a codominio non compatto. Rendiconti del Seminario Matematico della Universita di Padova 1955;24:8492.

110. Arino O, Gautier S, Penot JP. A fixed-point theorem for sequentially continuous mappings with application to ordinary differential equations. Funkcial. Ekvac. 1984;27(3):273-9.

111. Kubiaczyk I. On a fixed-point theorem for weakly sequentially continuous mapping. Discussiones Mathematicae, Differential Inclusions, Control and Optimization. 1995;15(1):15-20.

112. Hebson G, Earnshaw J, Marchington L. Too emotional to be capable? The changing nature of emotion work in definitions of 'capable teaching'. Journal of Education Policy 2007; 22:675-94.

113. Kisiolek A, Kubiaczyk I. Asymptotic behaviour of solutions of nonlinear delay difference equations in Banach spaces. International journal of mathematics and mathematical sciences 2005; 2005:2769-74.

114. Mitchell AR, Smith C. An existence theorem for weak solutions of differential equations in Banach spaces. InNonlinear equations in abstract spaces 1978 Jan 1 (pp. 387-403). Academic Press.

115. Travers CJ, Cooper CL, Cary C. Teachers under pressure: Stress in the teaching profession. Psychology Press 1996.6.

116. Ball JM. 23. - Weak Continuity Properties of Mappings and Semigroups. Proceedings of the Royal Society of Edinburgh Section A: Mathematics. 1975;72(4):275-80.

Submission: January, 25, 2020

Revision received: February 18, 2020 Accepted for publication: February 18, 2020 